\title{
PERÚ-CHILE: SÍNDROME POSTBÉLICO
}

\author{
Martín Nizama V. ${ }^{1}$ \\ instituto Nacional de Salud Mental Honorio Delgado - Hideyo Noguchi, Lima, Perú \\ (RECiBIDO El 25/11/2009, ACEPTADo el 21/12/2009)
}

\begin{abstract}
RESUMEN
A propósito del espionaje perpetrado por Chile contra el Perú entre el 2004 y el 2009, se examinan algunas características del belicismo, el armamentismo y el expansionismo geopolítico de Chile, tras la guerra del Pacífico (1879) que cercenó a Bolivia y Perú las provincias de Antofagasta, Tarapacá y Arica. En adelante, la historia entre Chile y Perú se desarrolló en base a la relación dicotómica vencedor-vencido en la cual, por un lado, prevalecen recurrentes actitudes de soberbia, prepotencia, amenazas, armamentismo desenfrenado, hostilidad y belicismo, azuzado por el codicioso militarismo pinochetista de determinadas castas castrenses que aún ejercen un enmascarado tutelaje sobre la democracia chilena, y por el otro lado, el resentimiento, la desconfianza y el temor presente entre los peruanos. Esta realidad se ha vuelto a poner en evidencia con el descubrimiento de una red de espionaje contra el Perú pagada por Chile, al haber contratado los servicios de un agente militar peruano en actividad para dicho propósito. Esta disfuncionalidad en la relación bilateral a lo largo de 130 años, ha generado como secuela un síndrome postbélico en el cual el vencedor de la confrontación bélica se siente superior y subestima al vencido, considerándolo inferior, habiéndose establecido una irresuelta relación de envidia-agresividad versus resentimiento-miedo, lo cual alimenta los planes expansionistas de Chile; primero, en el terreno económico, comercial o empresarial para luego hacerlo militarmente, para lo cual se arma. Tras la conclusión se proponen algunas alternativas para afrontar el síndrome postbélico.
\end{abstract}

Palabras clave: armamentismo, belicismo, expansionismo geopolítico.

\section{ABSTRACT \\ PERU-CHILE: POST WAR SYNDROME}

In regard to the espionage committed by Chile against Peru between 2004 and 2009, this article examines some characteristics of the militarism, the arms race and geopolitical expansion of Chile, after the Pacific War (1879) that separated from Peru and Bolivia the provinces of Antofagasta, Tarapacá and Arica. Henceforth, the history between Chile and Peru, was developed based on a dichotomous victor-vanquished relationship in which prevails attitudes of pride, arrogance, threats and unbridled arms race, hostility and warmongering, militarism fueled by the greedy Pinochetist military caste that still exert a masked tutelage on the Chilean democracy, and on the other hand, resentment, mistrust and fear present among Peruvians. This reality has become a highlight in the discovery of a spy ring against

1 Médico Psiquiatra del Instituto Nacional de Salud Mental "Honorio Delgado - Hideyo Noguchi" de Lima, Perú. E-mail: maniva@terra.com.pe 
Peru paid by Chile, having engaged the services of a peruvian military officer in service for the purpose. This dysfunction in bilateral relations over 130 years, has generated a post war syndrome in which the winner of military confrontation feels superior to the vanquished who is underestimated and considered substantially lower, establishing an unresolved relationship based on envy aggression versus resentment fear, which feeds the expansionist plans of Chile, primarily in the economic, trade or business field, and thereafter militarily, for which they arm themselves. Following the conclusion, some alternatives are suggested for dealing with the post-war syndrome.

Keywords: armamentism, belicism, geopolitical expansionism.

\section{INTRODUCCIÓN}

Chile es una pequeña nación con una población de 17 millones de habitantes. Histórica y geopolíticamente es un país prepotente y expansionista, sin respeto por sus vecinos. A continuación, de manera sucinta se mencionan algunos hechos trágicos precedentes. Así, por la posesión del Cusco, el 6 de abril de 1538, las tropas de Hernando y Gonzalo Pizarro ("los de Pachacámac") derrotaron a las huestes de Diego de Almagro ("los de Chile") en la batalla de Salinas, ubicada a $5 \mathrm{~km}$ del sur del Cusco. Al respecto Raúl Porras Barrenechea, escribió: "la guerra de las Salinas fue, en verdad, la primera guerra del Pacífico. Pizarro, quien murió asesinado en su palacio por "los de Chile" por no querer entregar la Nueva Toledo, murió en realidad defendiendo la integridad territorial del Perú" (2). Hace 130 años, tras la infausta guerra de rapiña (1879-83) perpetrada de manera artera contra sus "hermanos" (3) latinoamericanos, Perú y Bolivia; luego del saqueo de la heredad nacional, Chile duplicó su territorio al anexarse Antofagasta, Tarapacá y Arica, se posesionó para su usufructo de las riquezas del salitre y el guano, quedándose hasta la actualidad con el monitor Huáscar como trofeo de guerra. Esta oprobiosa enajenación fue cometida con el tutelaje y apoyo convenido del imperio inglés, en cumplimiento de la visión geopolítica de su mentor ideológico Diego Portales, quien antes de ser asesinado instigó la disolución de la Confederación Perú-Boliviana, al considerarla una amenaza para la supervivencia de Chile. La Confederación se disolvió luego de su derrota en la batalla de Yungay por las huestes chilenas.

Desde el comienzo de su historia republicana, las políticas de Estado de Chile en sus relaciones bilaterales con el Perú han mantenido una misma coartada: el "armamentismo disuasivo". Así, una década antes de la guerra del Pacífico, ese país inició una carrera armamentista que le permitió tener la supremacía naval en el Pacífico al adquirir los acorazados Cochrane (1874) y Blanco Encalada (1876), con la argucia de que era una política disuasiva contra una fantasmal conspiración peruano-boliviana. Sergio Villalobos, historiador chileno, acerca del armamentismo sureño previo a la guerra del Pacífico, lo justificó de esta forma: "Vale la pena destacar que los temores peruanos y bolivianos sobre una supuesta política agresiva de Chile probaron ser completamente infundados. El gobierno no albergaba ningún plan siniestro. La superioridad naval era un simple resguardo nacional y no fue empleada para dar ningún golpe ni ejercer amenaza”. En la actualidad, con el manido ardid de la modernización del equipo bélico y defensa de sus fronteras, Chile ha emprendido una desaforada inversión económica en una carrera 
armamentista, a la espera del fallo de la Corte Internacional de Justicia de La Haya, coyuntura en la cual prevé activar su potencial bélico, si el fallo le fuera adverso. En la misma forma en que lo hicieron una centuria antes, Cristian Leyton, geoestratega chileno, acerca del armamentismo sureño actual, lo justificó así: “Chile al no poseer demandas territoriales con sus vecinos ni tampoco ejercer una política de potencia hegemónica sobre el espacio regional o vecinal, ni menos aún una de expansión ideológica fuera de sus fronteras, no genera amenaza para la paz internacional. No existen fundamentos que permitan a Perú "acusar" a Chile estar embarcado en una carrera armamentista"(4).

Por su lado, el maestro sanmarquino Raúl Porras Barrenechea efectuó un agudo, objetivo y aún vigente análisis crítico sobre la infausta guerra del Pacífico (1879). Él señaló que: "En la guerra con Chile los estadistas no prepararon la defensa y confiaron en los medios pacíficos y diplomáticos. Chile preparó sistemáticamente la agresión, tuvo la iniciativa de las operaciones y la ofensiva estratégica" (5).

En la actualidad, no obstante los rigores de la gran recesión económica mundial, Chile continúa armándose militarmente en forma desmesurada y desproporcional, con ambiciosos objetivos expansionistas mirando fijamente al Perú, fiel a la enseña de su escudo nacional y lema patrio que reza "por la razón o la fuerza". De este modo, siembra la desconfianza y la inseguridad en la convivencia entre ambas naciones supuestamente hermanas. Chile tiene como visión misión convertirse en el más breve plazo posible en la potencia hegemónica del Pacífico Sur, en desmedro del Perú.

Ha fracasado, pues, la política de cuerdas separadas ensayada por los gobernantes peruanos; puesta en marcha de modo que el tema contencioso de La Haya vaya por un lado; y paralelamente las relaciones comerciales y empresariales de las crecientes inversiones chilenas en el Perú, vaya por el otro lado. Chile utilizó esta confiada y porfiada política peruana, para avanzar en sus propósitos invasivos y posesionarse de gran parte del mercado peruano. Al punto que sus inversiones en el Perú actualmente exceden los 7203 millones de dólares. Sin embargo en Chile, los capitales peruanos no tienen un trato recíproco y su presencia es infinitamente menor. Ni siquiera la masiva migración de más de 130 mil peruanos a ese país ha contribuido a generar confianza en las castas castrenses chilenas. Son insaciables en sus expectativas de expansionismo geopolítico a costa del Perú.

En suma, las relaciones bilaterales tienen la impronta de la desconfianza y el recelo; contexto en el cual toda política bien intencionada de pacificación y limitación del armamentismo, fracasa inexorablemente. El último acto de infraternidad ha sido el descubrimiento de una red de espionaje para la compra sistemática de información de secretos militares, lo cual ha indignado al Perú justificadamente, y Chile sólo responde con la estratagema de negar o minimizar todo para proteger su imagen internacional. El espionaje es tipificado en el derecho internacional como acto hostil. De esta manera, Chile respondió deslealmente a la política bien intencionada del presidente García cuya prédica ad populum es: "menos armas dan como resultado menos pobreza". Por estos hechos precedentes, Chile es digno de confianza cero para la inmensa mayoría de peruanos, que lo perciben como una amenaza real e inminente para la seguridad nacional.

De otro lado, en circunstancias por demás extrañas, el 12 de noviembre del 2009 se filtró en la prensa nacional la noticia del espionaje chileno, perpetrado a través de un agente 
peruano, apoyado por una red encubierta con ramificaciones en Santiago y Lima, lo cual fue el detonante de una crisis bilateral de resonancia continental.

\section{ANTECEDENTES DE ESPIONAJE}

Hace 30 años, el 20 de enero de 1979, el ex suboficial FAP de tercera, Julio Vargas Garayar, fue fusilado por actos de traición a la patria al efectuar espionaje a favor de Chile. Él, fue descubierto tomando fotos de la base militar de La Joya (Arequipa). El embajador chileno de esa época, Francisco Bulnes, fue declarado persona no grata y expulsado del país por este motivo. En diciembre de 1978, dos oficiales navales chilenos, Sergio Jarpa Gerhard y Alfredo Andoházegui fueron capturados cuando tomaban fotos de aviones en la base FAP de Talara. En 1995, Chile, siendo garante del Protocolo de Río de Janeiro, vendió secretamente armas al Ecuador durante el conflicto del Cenepa.

Y, en el 2003, la víctima de esta tradición chilena de espiar fue Argentina. En esa oportunidad, José Andrés Basbus, cónsul adjunto argentino en Punta Arenas, sorprendió a dos sujetos en el consulado argentino en un acto de espionaje. Uno de ellos dejó caer un documento de identidad que lo identificó como Luis Alberto Robles Ricus, agente chileno de contrainteligencia. Sin embargo, sus dirigentes políticos tienen la desfachatez de pregonar que su país no practica el espionaje, y afirman que el suyo es un país serio y como tal, poseedor de un sólido prestigio internacional.

Durante la guerra de Las Malvinas en 1982, Chile apoyó a Inglaterra en contra de Argentina, siendo ésta una nación vecina, latinoamericana y cuna del libertador José de San Martín. El 16 de enero del 2008, el Perú presentó una demanda por la delimitación marítima ante la Corte Internacional de Justicia de La Haya y Chile la calificó de acto inamistoso. En setiembre del 2009, el ministro de defensa de Chile, Francisco Vidal, mediante declaraciones ofensivas se mofó del pacto de no agresión propuesto por el presidente del Perú, Alan García Pérez.

\section{ESPIONAJE}

\section{Red de espionaje}

El técnico inspector suboficial FAP, Víctor Ariza Mendoza, (VAM, 45 a, n. Huacho), perteneciente a la Dirección de Inteligencia de la FAP, trabajó como asistente en la agregaduría aérea del Perú en la embajada peruana en Santiago de Chile entre febrero y diciembre del 2002, año en que fue captado por los servicios secretos de ese país, en el Círculo de Auxiliares de las Fuerzas Armadas y Policiales Extranjeros Acreditados en Chile (CAFAPE), en cuyo ámbito confraternizan agentes de inteligencia que laboran en las agregadurías militares que prestan servicios en Santiago, al cual VAM perteneció durante siete años. Mas, él admitió que realizó acciones de espionaje para Chile solamente a partir del 2004. VAM fue denunciado ante sus superiores en el 2007 al mostrarse un voucher de depósitos bancarios a su nombre, procedentes de Chile, como pago porque proporcionaba información clasificada a ese país (La Primera, 15 de noviembre, 2009). Sin embargo, 
recién después de más de dos años, el viernes 30 de octubre del 2009, VAM fue capturado en un restaurante de Jesús María, mientras degustaba plácidamente sus alimentos en compañía de unos amigos. En este espionaje financiado desde el exterior, inicialmente los instigadores chilenos le habrían pagado al traidor entre 5 mil y 8 mil dólares mensuales, a cambio de proveerles información clasificada de los secretos militares peruanos, y desde setiembre del 2005 un promedio de 3 mil dólares mensuales y bonificaciones especiales de hasta 10 mil dólares cuando hacía envíos de información especialmente solicitados; dinero que le era transferido mediante la agencia Western Union. VAM laboró como espía a favor de Chile hasta el 2009. El sueldo global de un suboficial FAP es de 667 dólares mensuales. Las investigaciones policiales indican que le habrían descubierto cuentas bancarias en las cuales tendría depositados 178 mil dólares. Además, le detectaron propiedades inmuebles en los distritos de San Martín de Porres, Surco y Puente Piedra. Sus enlaces militares chilenos eran los miembros en retiro de la Fuerza Aérea de Chile, el comandante Adrián Bravo Carrasco (alias "Daniel Márquez Torrealva”) y el suboficial mayor Jaime López Ruiz (alias "Víctor Vergara Rojas"), quienes le remesaban el dinero. Por este motivo, VAM hizo varios viajes a Chile, vía Argentina. Se reunía con sus contactos en Arica, Buenos Aires, Montevideo y Asunción.

El felón habría entregado a los operadores chilenos el Plan Estratégico Institucional de la FAP destinado a optimizar la operatividad de esa institución hasta el 2021; así como la relación de estudiantes de la Escuela de Inteligencia de la FAP. También vendió el Plan Estratégico Quiñones (reequipamiento FAP), Plan Estratégico Bolognesi (reequipamiento del Ejército), el Plan Estratégico Grau (reequipamiento de la marina) y los secretos del Núcleo Básico de Defensa (NBD), cuyo objetivo es alcanzar en el período 2007-2011 un nivel de operatividad de las Fuerzas Armadas, capaz de responder y resistir durante un período prudente una eventual agresión externa (La República, 15 de noviembre, 2009). Por ello, Chile ha duplicado su arsenal bélico. El caso Ariza es sólo la punta del iceberg de una extensa red de espionaje chileno instrumentado en nuestro país, no se sabe de qué dimensiones y consecuencias.

En el mismo sentido, se ha detectado que un número indeterminado de pilotos de la Fuerza Aérea de Chile (FACH) opera en la empresa LAN (de bandera chilena) que cotidianamente vuela por los aires del cielo peruano por tiempo indefinido, lo cual pone en riesgo la seguridad nacional. Stricto sensu, la Ley debe impedir que pilotos extranjeros operen en aerolíneas de bandera nacional. En la actualidad, mientras 143 pilotos chilenos, algunos de ellos, miembros activos de la FACH, laboran en la empresa LAN, más de 300 pilotos peruanos se encuentran desempleados. Los riesgos contra la seguridad nacional, por este motivo, son: dependencia de los pilotos extranjeros con sus fuerzas armadas de origen, posibles actos de espionaje y actos de sabotaje en el territorio nacional. Estos hechos revelan un encubierto ánimo belicista en los vecinos del sur.

\section{Perfil del felón}

VAM fue reclutado por los servicios de espionaje chilenos porque reunía el perfil adecuado para desempeñarse en tan vil función contra su madre patria: cobardía, carencia de identidad nacional, sujeto manipulable, urgencias económicas debido a su bajo sueldo y relación 
con múltiples parejas sentimentales, por lo cual estaba obligado a proveer la manutención de varios hogares.

\section{Reacción peruana}

La respuesta peruana fue rápida y enérgica: llamar a consulta al embajador peruano en Santiago, Carlos Pareja Ríos; cancelar la visita de la ministra de la producción, Mercedes Araoz, quien la siguiente semana se iba a reunir con la presidenta chilena para entregarle la propuesta peruana, orientada a frenar el gasto en armamento en la región; cancelar la reunión presidencial García-Bachelet en el marco de la XVII Reunión de Líderes del Foro de Cooperación Económica Asia Pacífico (APEC) de Singapur; así como el retorno anticipado del mandatario peruano a Lima, por este asunto imprevisto.

Desde Singapur, el canciller José Antonio García Belaunde manifestó que "se trata de un trágico, lamentable y repudiable caso de espionaje y un acto ofensivo del gobierno chileno al haber estado sufragando estas actividades en el Perú" (La República, 15 de Noviembre, 2009). El congresista Juvenal Ordóñez acotó que "la política de paz que se le está ofreciendo a Chile fue contestada con la compra de misiles, radares y encima espionaje" (La Primera, 16 de noviembre, 2009). Los peruanos pecan de ser muy confiados. Las principales autoridades nacionales se informaron del espionaje mientra se encontraban en el exterior, el presidente García en Seúl y el canciller García Belaunde en Singapur. Por su lado, el congresista Víctor Andrés García Belaunde comentó que de Chile, "ahora se espera el pedido de perdón y la promesa de que este tema no se volverá a repetir".

\section{Condena presidencial}

El 16 de noviembre de 2009, una vez acabada la sesión del Consejo de Seguridad Nacional, desde el Salón Dorado de Palacio de Gobierno, refiriéndose a un "hecho de espionaje por personas de Chile con la colaboración de un agente peruano", el presidente Alan García hizo un pronunciamiento en los términos siguientes: "Quiero expresar mi rechazo enérgico, categórico, a esta ofensa que se hace a la soberanía del Perú. Creo que estos son actos repulsivos que no corresponden a un país democrático y que dejan muy mal la presencia de Chile ante el mundo...sólo el débil apela a estas armas. Sólo el que se siente débil espía... en 1978-79 tuvimos un caso similar, lo que demuestra una continuidad en la forma de actuar". Y, acotó que cuando el Perú hizo una propuesta "de buena fe" para alcanzar un pacto de no agresión y lograr una limitación en la compra de armas, recibió una respuesta "destemplada y descortés" de algunos personajes de la política chilena, refiriéndose al ministro de defensa, Francisco Vidal, y al canciller Mariano Fernández, quienes dieron a entender que la propuesta estaba desfasada. Es sabido que Chile se niega a reducir los gastos armamentistas. En cuanto a las razones del espionaje chileno, el presidente peruano comentó que es "el complejo de quienes ven con temor el crecimiento del Perú, su desarrollo democrático y económico...Si este avance genera temor y complejo y origina este tipo de comportamientos propios de una republiqueta y no de un país democrático, nosotros lo lamentamos.... el Perú avanza y eso genera temor a los que creyeron ser siempre los adelantados y los abanderados del desarrollo". Luego 
apuntó que: "La Interpol podrá a través de todos sus medios y de su neutralidad, demostrar que el Perú hace estas afirmaciones sin caer en ninguna inexactitud". Y, refiriéndose al asunto contencioso en La Haya, precisó que: "Esto no se puede responder mostrando las armas. La corte de La Haya y lo que diga no se puede responder con juegos de guerra, mostrando los dientes acerados de las armas, porque esa no es una costumbre democrática". (El Comercio, 17 de noviembre del 2009). Una fraseología rimbombante, más para el consumo interno.

\section{Indignación ciudadana}

La población reaccionó con indignación e irritación ante la inveterada costumbre chilena de espiar militarmente al Perú. Se valora esta permanente actitud como un afán de dominación, de abuso o prepotencia de los sureños. El pueblo peruano no tolera la actitud agresiva y ambiciosa de la clase política chilena que sólo se limita a negar lo innegable y amenazar como lo hizo de manera desatinada y arrogante el ex presidente Eduardo Frei Ruiz-Tagle, quien manifestó que no iban a aceptar las descalificaciones del presidente García a la presidenta Bachelet.

Por este motivo, instituciones fundamentales del país se pronunciaron reflejando la indignación de la peruanidad por estos actos de prepotencia chilena contra el Perú. De esta manera, la institucionalidad salió en defensa de la dignidad nacional, denunciando los propósitos expansionistas del país sureño.

\section{Negación de Chile}

Como de costumbre los gobernantes mapochos han negado estas acciones encubiertas, y por el contrario asumen el rol de víctimas de un supuesto complot peruano. $\mathrm{Al}$ respecto, la gobernante chilena, Michelle Bachelet, rechazó que su país esté alentando en modo alguno una carrera armamentista. "Nunca en nuestro país ha habido ningún intento de carrera armamentista. Nosotros no nos hemos armado para un fin bélico”, afirmó. El canciller de Chile, Mariano Fernández, se limitó a informar a su homólogo peruano, canciller José Antonio García Belaunde que "ellos no conocen del tema, que solo saben lo que ha aparecido en la prensa peruana en estos días". Al día siguiente, Fernández, fiel a la tradición de su gobierno de negar todo, cínicamente declaró: "Queremos decir enfáticamente: Chile no tiene nada que ver en este caso, no tenemos ninguna información disponible que permita vislumbrar siquiera algún tipo de participación chilena"; e insinuando que se trataba de una burda maniobra mediática peruana para desacreditar a su país, dijo: "Le pedimos sobre todo a las autoridades peruanas, investigar a fondo el asunto y mantener serenidad para que la opinión pública sea informada con la verdad de lo que ha ocurrido entre funcionarios de las Fuerzas Armadas del Perú" (El Comercio, 17 de noviembre de 2009). Bufonesco ¿no? En el mismo sentido se expresó el ministro de defensa chileno, Francisco Vidal, quien afirmó que su país "no está en carrera armamentista", acotando que el presupuesto de compra de armas es "infinitamente inferior" a 665 millones de dólares. Por su lado, el general Ricardo Ortega, jefe de la Fuerza Aérea de Chile espetó que la captura del suboficial peruano, que supuestamente espiaba para Chile, demuestra el "interés de provocar" del Perú. 
La vocera del gobierno chileno, Carolina Tohá, minimizó el hecho manifestando que "cuando hay denuncias como esta, los gobiernos tenemos que ser prudentes y tenemos que ser serios. No corresponde que haya reacciones precipitadas ante antecedentes que no tienen fundamentos ni investigación que sea válida. Queremos ser muy claros, Chile no es espía, Chile es un país muy serio en sus relaciones internacionales". El senador chileno Sergio Romero, acotó: "Yo creo que de verdad Perú está pasándose de la raya, y estoy muy sorprendido de la actitud pasiva y simplemente observante de nuestra cancillería y el gobierno" (La República, 15 de noviembre de 2009).

Siguió una retahíla de declaraciones y comentarios prepotentes, amenazantes e injuriantes de políticos chilenos. Por ejemplo, del senador Jorge Pizarro, "El Perú va a seguir generando uno y mil incidentes donde Chile siempre aparece como un país agresor"; el senador Marcelo Díaz declaró: "García ha puesto en marcha una diplomacia odiosa, profundamente hostil a Chile" y agregó que era "un acto más de histrionismo al que nos tiene acostumbrados el presidente García. Llegó la hora de decirle al Perú jya está bueno de sus shows". Por su lado, el internacionalista y ex diplomático sureño, José Rodríguez Elizondo, añadió que el Perú tiene "la inquietud de que Chile no vaya a cumplir el fallo, una vez que sea derrotado en La Haya", y que el propósito de su estrategia es "fortalecer las fuerzas militares peruanas, bloquear el desarrollo de la fuerza militar chilena y convocar a una opinión pública regional y mundial para que haga causa común a favor del Perú" (El Comercio, 17 de noviembre de 2009).

\section{Victimización chilena}

Paradójicamente, la clase política de ese país en lugar de hacer un mea culpa y expresar sus excusas al Perú por la ofensa inferida mediante el espionaje, asume el rol de víctima y sin ambages acusa al Perú presentándolo en los medios nacionales e internacionales como autor de un burdo montaje. Las cúpulas del poder demuestran así pobreza ética y carencia de rectitud, demostrando lo contrario de lo que preconizan: ser un país serio, responsable y con un sólido prestigio en la comunidad internacional.

\section{BELICISMO}

\section{Estrategia intimidatoria}

Las cúpulas belicistas chilenas no pierden ocasión para deslizar amenazas contra la soberanía ofendiendo la dignidad nacional. Pinochet solía alentar a sus empresarios a invertir en el Perú, diciéndoles de manera socarrona que el Perú estaba en venta, lo venden barato les manifestaba y les aseguraba que el ejército chileno garantizaba sus inversiones. Por estas razones, la congresista e intelectual peruana Martha Hildebrandt, de manera metafórica definió a Chile como una espada en América del Sur, destinado a ser siempre agresor, al estar enclaustrado entre los Andes, la Patagonia, el mar y el Perú. Sólo mira al Perú y busca intimidar a los peruanos. De modo que Chile busca pretextos para justificar un ataque armado al Perú. 


\section{Armamentismo}

Chile es el país que más ha gastado en adquirir armas de última generación en Latinoamérica, con una inversión total de 20 mil millones de dólares. El 13 de noviembre de 2009, la Agencia de Cooperación de Seguridad y Defensa de Estados Unidos notificó al Congreso de ese país sobre posibles adquisiciones militares chilenas por 665 millones de dólares: lanzadores Avenger, misiles Stinger, misiles aire-aire AIM de mediano alcance y sistemas de radar Sentinel. El ministro de defensa chileno Francisco Vidal recurrió a la consabida justificación de que era para sustituir el material obsoleto de sus FF.AA. y que ello no alteraba el equilibrio estratégico de la región. En abril pasado, Chile compró a Holanda 28 aviones cazabombarderos F-16, modificados con tecnología israelí por 270 millones de dólares. En el último quinquenio, Chile ha incrementado sus gastos militares en un $49 \%$, desacatando el artículo 2 de los Estatutos de la OEA, el cual establece el compromiso de todos los países miembros de limitar los gastos militares para aplicarlos al desarrollo económico y social.

En la última década ha adquirido más de 350 tanques Leopard I y II (los tanques más poderosos de América Latina), aviones cazabombarderos F-15 y más de 40 aviones F-16 con sistemas de misiles aire-aire de alcance medio, dos submarinos equipados con dispositivos de disparo de misiles y ocho fragatas. Entre los gobiernos de Lagos y Bachelet, ha invertido más de 5 mil millones de dólares en adquisición de armas ofensivas.

Según el informe del Instituto Internacional de Estudios para la Paz de Estocolmo (SIPRI, 2007), con una inversión de 615 millones de dólares, Chile fue el segundo importador de armas de América Latina después de Venezuela, con la diferencia de Chile ha optado por la tecnología más avanzada; mientras que Venezuela se ha centrado en material para armar a su población civil.

Chile ha informado que se arma para proteger sus inversiones, las mismas que aceptadas por Perú equivalen a hacerse el harakiri. En Chile, la Ley del Cobre destina un presupuesto exclusivo que representa el $10 \%$ del valor de las exportaciones de cobre al presupuesto de las fuerzas armadas para la adquisición de material bélico. En la actualidad, la correlación de fuerzas entre Chile y Perú es de diez a uno.

Por este motivo, el canciller peruano José García Belaunde manifestó: "Consideramos que el nivel de compras de armamento que hace Chile es un problema y un motivo de seria preocupación. No entendemos por qué Chile gasta tanto en armas y por qué esas armas están mirando al Perú. Tenemos una preocupación legítima por el nivel de gasto que en los últimos años ha tenido Chile para comprar armamento" (5 de diciembre de 2009, Página 12, Argentina).

\section{Desequilibrio militar en la región}

Chile cuenta con el arsenal bélico más moderno de la región y su capacidad armamentista dista mucho de las amenazas que pueda tener a su alrededor. Ninguno de sus vecinos ha demostrado históricamente vocación belicista. Sin embargo, Chile sí tiene obsesión expansionista. Según SIPRI, Chile espera que en el 2010 sus FF.AA. se equiparen a las de la OTAN, nada menos. El poderío bélico es narcisista y siempre es un peligro inminente para la paz de los pueblos. 


\section{POSICIONAMIENTO ECONÓMICO}

\section{Inversiones asimétricas conflictivas}

Las inversiones bilaterales son fuertemente asimétricas a favor de Chile. La inversión chilena en el Perú excede los 7,203 millones de dólares; mientras que la inversión peruana apenas llega a los 1,005 millones de dólares. Con el apoyo de peruanos venales y rentistas, Chile se está adueñando de los recursos, empresas y puertos estratégicos, aprovechando la inconsciencia de la población, carente de identidad nacional. Aparte del TLC, celebrado sin la aprobación del Congreso Nacional, tiene la concesión de LAN (principal línea aérea del Perú de bandera chilena), Ripley, Falabella, Sodimac, Fasa, entre otras. Igualmente, capitales chilenos participan en la empresa Terminales Portuarios Euroandinos concesionaria del puerto de Paita, donde nació el héroe Miguel Grau. Además, que el gobierno cerró la Escuela de Aviación Civil; en un proceso escandaloso vendió a precios subvaluados los 642, $874.03 \mathrm{~m}^{2}$ del aeroclub de Collique (Comas) a empresas de capitales peruano-chilenos. Su próximo objetivo es hacerse de los yacimientos de gas; puesto que Chile tiene necesidades energéticas imperiosas. Las limitadas inversiones peruanas en Chile son de los grupos Brescia, Wong, Romero y de los empresarios gastronómicos. Según el economista Humberto Campodónico, "la cuestión es que cuando las inversiones son fuertemente asimétricas, la preocupación del país con mayores inversiones se orienta a protegerlas; [...] en lugar de que las inversiones lleven a la convergencia (en abstracto) pueden llevar a conflictos". Por eso en el TLC Perú-Chile se ha establecido lo que Chile ha impuesto: si existiera conflicto entre el Estado y un inversionista, este se resolvería con arbitraje internacional, lo cual obviamente favorece más al país con mayores inversiones (1). Estamos, pues, en una condición asimétrica muy peligrosa.

En esta coyuntura, el Ejecutivo debe cesar la suscripción de contratos, convenios, tratados, concesiones y acuerdos de orden económico y de cualquier otra índole con Chile, principalmente, inversiones en actividades estratégicas, verbi gratia: puertos, aeropuertos, energía eléctrica, gas, petróleo, minerales, tierras cultivables y vías de comunicación, entre otros.

\section{La Haya}

Ante la prepotencia chilena de mantener ocupadas zonas de mar que no son suyas, desoyendo los reclamos peruanos que demandaban la devolución pacífica de la porción de mar que le corresponde, el Perú tuvo que recurrir ante la Corte Internacional de Justicia de la Haya, por la delimitación marítima. Chile, descalificó la justa petición peruana ante el tribunal arbitral, valorándola como inamistosa.

\section{Posición pacifista del Perú}

Perú, al percatarse de las intenciones chilenas, ha propuesto ante el contexto internacional un acuerdo de no agresión que implica limitación del armamentismo para priorizar la lucha contra la pobreza y el desarrollo social a favor de los menos favorecidos. Mas, inicialmente, la inveterada codicia chilena hizo oídos sordos de esta plausible iniciativa. 


\section{SÍNDROME POSBÉLICO}

\section{Psicodinamia}

La secuela mayor que ha quedado de la oprobiosa invasión bélica chilena al Perú, es el sentimiento de superioridad que ostenta el vencedor; y a la par, el sentimiento de inferioridad que adquiere el vencido, tras una confrontación bélica internacional, con la consecuente actitud soberbia y prepotente del ganador y la subestimación al perdedor de la guerra; todo lo cual perdura en el tiempo. Subyace a esta constante, una irresuelta relación de envidiaagresividad de un lado y el de resentimiento-miedo por el otro. Esta fijación pática es el causante de una relación de hostilidad versus desconfianza entre ambos países. He aquí algunas manifestaciones de este síndrome postbélico:

\section{Cautiverio del Huáscar}

Símbolo de la guerra del Pacífico, desde el combate de Angamos (8 de octubre de 1879), el monitor Huáscar permanece en poder de Chile. Actualmente, es un museo flotante en el puerto de Talcahuano. Un gesto tangible de hermandad entre ambos pueblos debería ser la devolución al Perú de esta nave histórica donde se inmolaron el almirante Miguel Grau Seminario y los comandantes chilenos Arturo Prat y Manuel Thomson.

\section{Pinochetismo}

De manera enmascarada, el aún dominante militarismo pinochetista continúa ejerciendo tutelaje sobre la democracia en el país sureño. La clase política de ese país se encuentra sujeta a los designios autocráticos de la cúpula castrense inspirada en la ideología pinochetista, esencialmente antidemocrática, belicista y expansionista. De modo que la política chilena tiene ese trasfondo de poseer una democracia tutelada. Ello explica el doble discurso de su beligerante clase dirigente. Agentes pinochetistas asesinaron al ex presidente demócrata de ese país, Eduardo Frei Montalva, el 22 de enero de 1982, según lo reveló después de 27 años de impunidad la justicia chilena.

\section{Soberbia}

Los dirigentes políticos chilenos no pierden la oportunidad de expresarse de manera arrogante y peyorativa cuando emiten sus opiniones controversiales o disienten con las posiciones peruanas. Muestran un anacrónico sentimiento de superioridad que han asumido de por sí y ante sí como secuela de la guerra del Pacífico. Se han quedado fijados a esa experiencia histórica de hace 130 años; sin embargo, fungen de modernos y acusan a los peruanos de estar poseídos de odio antichileno y por ende, de una actitud revanchista. De esta manera ellos subestiman a los peruanos.

\section{Hostilidad}

La Operación Salitre 2009, de ejercicios militares realizados en el frente norte de su país, fue un acto de prepotencia que motivó justificadas protestas del gobierno peruano. El nombre 
"Salitre", era una provocadora alusión a la guerra del salitre del siglo XIX. Sin embargo, de manera paradójica enrostran a los peruanos de vivir fijados a experiencias traumáticas del pasado. Así mientras ellos se preparan para la guerra, el Perú se muestra como un país pacifista. Al respecto, el constitucionalista y congresista Javier Valle Riestra puntualizó que "la posición chilena es completamente distinta, es una posición expansionista y la carrera armamentista en la que se encuentra indica que tenemos un enemigo realmente peligroso" (La Primera, 16 de noviembre, 2009).

\section{Belicismo subliminal}

La película Epopeya en la que ellos mostraron su versión unilateral sobre la guerra del Pacífico, fue una forma sutil de azuzar en el pueblo chileno sentimientos bélicos, como preparándolos subliminalmente para una nueva edición de ese irrepetible zarpazo oprobioso.

\section{Enajenación de la identidad nacional}

En la profundización de su estrategia invasiva total, Chile comenzó a patentar como originarios suyos algunos productos comerciales de bandera del Perú; p.e. diversas variedades de papa, el pisco, el suspiro limeño; con el propósito de erosionar la identidad nacional y debilitar el sentimiento de peruanidad. Todo ello, dentro de una estrategia global de dominación del Perú.

\section{Clase dirigente chilena}

La clase dirigente chilena es codiciosa y agresiva, cuyo leitmotiv al parecer es la ambición por la diversidad de riquezas y maravillas que posee el Perú; amén de su malquerencia por la admirable historia milenaria del Perú de la cual que ellos carecen. De ahí que sus castas militares cultiven sueños expansionistas para despojar al Perú de lo suyo; aun a costa de poner en riesgo la paz regional. Esa clase dirigente ambiciosa ha educado al pueblo chileno con la ideología expansionista de sentirse con derecho a usurpar aquello que no les pertenece. De ahí su voraz fijación en el Perú.

\section{Clase dominante peruana}

A diferencia de Chile, el Perú carece de clase dirigente. Tiene clase dominante, la cual suele ser rentista, ególatra y parasitaria. Se enriquece a costa del trabajo del pueblo importándole muy poco el destino de la nación, las amenazas externas e internas. De modo que la clase política que gobierna el país se limitan a dejar hacer, dejar pasar; y que los problemas sociales se embalsen hasta que se resuelvan solos o estallen violentamente: dentro, la corrupción, la pobreza y el fundamentalismo narcosenderista que azota el país y afuera, la amenaza de embestida chilena fortalecida por el infraterno acecho ecuatoriano y boliviano. Es tiempo de que el Perú tenga una clase dirigente que asuma con coraje, dignidad y grandeza los retos del Perú, para poner punto final a la recurrente prepotencia y avasallamiento de Chile. La dignidad nacional es un valor tan preciado como la soberanía. 
Martin Nizama V.

\section{Identidad nacional}

Las clases dominantes, las castas políticas, los caciques y caudillos, y el pueblo con escasa educación, carecen de un auténtico sentimiento de peruanidad; de apego y defensa de lo propio; de una sólida autoestima y conocimiento cabal de la historia de la nación. Por ello, el pueblo no diferencia lo nacional de lo extranjero; y por el contrario, se autosubestima y sobrevalora lo foráneo en desmedro de lo propio.

\section{CONCLUSIÓN}

En la actualidad el Perú se encuentra militarmente en la indefensión. De manera progresiva, Chile está invadiendo al Perú en todo terreno: comercial, empresarial, agroindustrial, portuario, recursos estratégicos, espionaje y enajenación de la identidad nacional, entre otras modalidades. Aunque lo niega reiteradamente, a la luz de los hechos Chile no es confiable. Se prepara para atacar el Perú, teniendo como pretexto el diferendo limítrofe marítimo, la protección de sus intereses económicos o cualquier otra coartada. Para ello, se arma de manera desproporcionada e injustificada. Es una amenaza real para la seguridad nacional. Tiene alianza estratégica con Bolivia, país que también se está armando con miras a lograr una salida al mar y cuyo Presidente agrede de manera frecuente e injustificada al Perú. De inmediato el Perú debe reestructurar sus relaciones con Chile, sin candidez ni sumisión; establecer alianzas estratégicas internacionales y denunciar esta amenaza en los foros internacionales competentes. Las guerras son confrontaciones de lesa humanidad que deben ser exterminadas por las fuerzas de la paz mundial y condenadas por los organismos mundiales multilaterales.

En el más breve plazo posible, el Perú debe poner fin al permanente trato prepotente y vejatorio por parte de la clase dirigente y de las castas militares pinochetistas de Chile; puesto que ello lacera profundamente la autoestima y la dignidad de los peruanos, lo cual socava la identidad nacional, en desmedro del desarrollo de la nación peruana.

Igualmente, debido a la situación de pobreza, oscurantismo mental y a sus lastres históricos, el pueblo peruano no tiene la visión de convertirse en un país desarrollado, del primer mundo. Falta educación y amor al Perú. Además, cabe recordar que se hace patria con educación y sin corrupción. Y, el ejemplo proviene del vértice del poder.

\section{ALTERNATIVAS}

Para poner fin a esta situación de oprobio tolerado por la clase política nacional, se proponen algunas alternativas a ser desarrolladas por parte del Estado, la institucionalidad, la sociedad civil y el colectivo nacional poseedor de conciencia cívica y nacional:

1. Adoptar el estado de alerta por el riesgo de un ataque relámpago de parte de Chile.

2. Definir claramente los objetivos geopolíticos del Perú a corto, mediano y largo plazo.

3. Cohesión sólida del pueblo peruano, manteniéndolo informado objetivamente. 
4. Pronunciamiento claro y contundente del Perú pensante.

5. Movilización del pueblo peruano para que la historia no se repita.

6. Vigilar al máximo las relaciones bilaterales con Chile.

7. Revisión del TLC con Chile en el Congreso Nacional.

8. Denunciar el espionaje chileno ante la comunidad internacional: OEA, ONU, UE, UNASUR, desenmascarando sus propósitos belicistas y expansionistas.

9. Potenciar la capacidad disuasiva de las FFAA peruanas.

10. Cesar la compra de productos en los centros comerciales chilenos.

11. Hacer conocer plenamente a los niños y jóvenes la milenaria y rica historia nacional.

12. Educar a los niños y adolescentes de todos los estamentos sociales en los valores nacionales y veneración de los símbolos patrios.

13. Desarrollar de manera activa, intensiva y personal la autoestima de los peruanos.

14. Desarrollar sistemáticamente el sentimiento de peruanidad en la niñez y juventud.

15. Hacerse respetar por sí mismo ante los países vecinos.

16. Hacer del Perú un país pacifista que se hace respetar en el contexto internacional.

17. Involucrar al pueblo en el compromiso de hacer del Perú un país desarrollado.

\section{REFERENCIAS BIBLIOGRÁFICAS}

1. Campodónico, Humberto. Perú-Chile: Inversiones asimétricas y conflictos. La República, 16 de noviembre de 2009. Lima.

2. López Martínez, Héctor. La batalla de las Salina y sus víctimas. El Comercio, 25 de noviembre de 2009.

3. López-Merino, Ignacio (2008). Sangre de hermanos. Lima: Editorial Planeta.

4. Porras Barrenechea, Raúl (1955). Fuentes históricas peruanas (Apuntes de un Curso Universitario). Lima: Juan Mejía Baca \& P.L. Villanueva editores. 